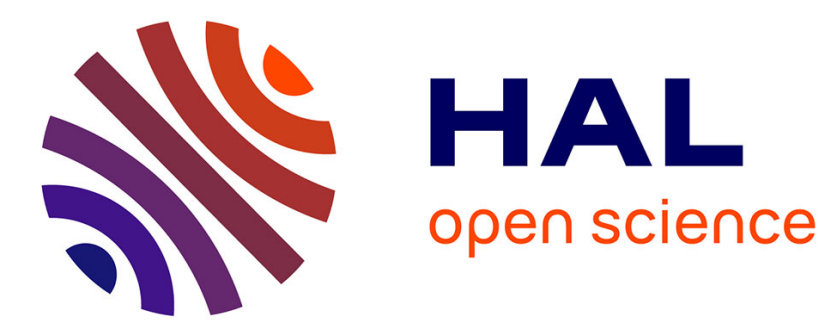

\title{
Emission of titanium dioxide nanoparticles from building materials to the environment by wear and weather
} Neeraj Shandilya, Olivier Le Bihan, Christophe Bressot, Martin Morgeneyer

\section{To cite this version:}

Neeraj Shandilya, Olivier Le Bihan, Christophe Bressot, Martin Morgeneyer. Emission of titanium dioxide nanoparticles from building materials to the environment by wear and weather. Environmental Science and Technology, 2015, 49 (4), pp.2163-2170. 10.1021/es504710p . ineris-01855008

\section{HAL Id: ineris-01855008}

\section{https://hal-ineris.archives-ouvertes.fr/ineris-01855008}

Submitted on 25 Sep 2018

HAL is a multi-disciplinary open access archive for the deposit and dissemination of scientific research documents, whether they are published or not. The documents may come from teaching and research institutions in France or abroad, or from public or private research centers.
L'archive ouverte pluridisciplinaire HAL, est destinée au dépôt et à la diffusion de documents scientifiques de niveau recherche, publiés ou non, émanant des établissements d'enseignement et de recherche français ou étrangers, des laboratoires publics ou privés. 


\section{Emission of Titanium Dioxide Nanoparticles from Building Materials to the Environment by Wear and Weather}

Neeraj Shandilya, Olivier Le Bihan, Christophe Bressot, Martin Morgeneyer*

Neeraj Shandilya, Dr. Olivier Le Bihan, Dr. Christophe Bressot

Institut National de 1'Environnement Industriel et des Risques (INERIS), Parc Technologique Alata BP 2, 60550 Verneuil-en-Halatte, France

E-mail: martin.morgeneyer@utc.fr

Neeraj Shandilya, Dr.-Ing. Martin Morgeneyer

Université de Technologie de Compiègne (UTC), rue Roger Coutollenc, 60200 Compiègne, France

\section{Abstract}

In the present work, we investigate the effect of the weathering duration on a commercial photocatalytic nanocoating on the basis of its nanoparticles emission tendency into the two media - air and water. It is found that the increase in the weathering duration results into the stepwise structural deterioration of the nanocoating which, in turn, decreases the nanocoating life, changes the nanocoating removal mechanism and increases the particle emission concentration. The emission of the free $\mathrm{TiO}_{2}$ nanoparticles is found to be weathering duration dependent. Three quantities- Emission Transition Pace (ETP), Stable Emission Level (SEL) and Stable Emission Duration (SED) are introduced. By linearly extrapolating these quantities from short weathering durations, the complete failure of the nanocoatings can be predicted and moreover the potential increase of nanoparticles release into the air.

Keywords: Weathering, Emission, Nanocoating

\section{Abstract Art}




\section{Introduction}

35 Photocatalytic nanocoatings are readily being applied on the external walls of buildings for their anti bacterial and self cleaning properties. ${ }^{1,2}$ These properties are ensured by the presence of embedded manufactured photocatalytic titanium dioxide $\left(\mathrm{TiO}_{2}\right)$ nanoparticles in the coating matrix. Resting on the external surfaces, these nanocoatings are frequently subjected to various mechanical solicitations and environmental weathering in real life conditions. ${ }^{3,4,5}$ As a result, the consequent loss in their structural integrity leads to their disintegration which, in turn, may lead to the exposure of embedded nanoparticles ${ }^{6}$ and thus their possible release too. Depending upon the type of medium in contact, this release can be into air as well as into ground waters. For a durable development, understanding their ecological and human health effects is important. In the last decade, slowly though, this concern has started gaining attention. ${ }^{6-19}$ In this context, various toxicological and ecotoxicological studies have also demonstrated toxic effects of some types of $\mathrm{TiO}_{2}$ nanoparticles. ${ }^{20-25}$

Here, the nanoparticles release from a commercial photocatalytic nanocoating is evaluated as a function of the duration of its weathering. Whilst the nanoparticles emission into air is studied via abrasion tests, their emission into water is studied via the microscopy and leaching tests of runoff samples. Through microscopic studies of the intermediate degraded states of the coated surfaces, the particles emission is shown to be weathering duration dependent.

\section{Materials and Methods}

\subsection{Samples}

For the study, a commercially available photocatalytic nanocoating, PHOTOCAL

MASONRY, was chosen. It is manufactured by NANOFRANCE Technologies, France. It consists of anatase titanium dioxide nanoparticles having a primary size of $<8 \mathrm{~nm}$ and a 
volume percentage of $1.1 \%$. Other material properties are as follows- Coagulation Index: $~ 2$; Appearance: white; Dispersant: Polymethylmethacrylate (PMMA). This type of nanocoating is fabricated specifically for the applications on porous surfaces like brick, concrete etc. The substrate chosen for the nanocoating application was a masonry brick $(11 \mathrm{~cm} \times 5 \mathrm{~cm} \times 5 \mathrm{~cm}$; Leopard brick, Ref: 901796, Castorama, France). It is basically an alumino-silicate brick which is frequently used in constructing façades, house walls, stairs etc. The microscopic analysis of the nanocoating and the substrate were carried out using Optical Microscope (Model Imager.M1m; Carl Zeiss MicroImaging GmbH; Germany), Energy Dispersion Spectroscopy (EDS; Model X-max; Oxford Instruments UK) and Transmission Electron Microscope (TEM; Model CM12; Philips, The Netherlands). Information on the microscopic analysis results are provided in the separately available supplementary part of this paper. Four coating layers with a total thickness of $80 \mu \mathrm{m}$ approx. were applied on the brick substrates. The substrate surfaces were prepared and the nanocoating was applied following the guidelines in the technical data sheet recommended by the nanocoating manufacturer (i.e. degreased using brush and ethanol soaked paper, dry and dust free surfaces; use of a High Volume Low Pressure spray during coating; $25^{\circ} \mathrm{C}$ of ambient temperature).

\subsection{Artificial weathering}

The artificial weathering tests were performed with the nanocoated and the uncoated reference brick samples in a weathering chamber (Model Suntest XLS+; Atlas; Germany). The artificial weathering consisted of maximum 2658 cycles (which corresponds to 7 months) of 2 hours each (120 min of UV light, 102 min dry, 18 min water spray). A xenon arc lamp (300-400 nm; 60 W/m²; Model NXE 1700; Ametek SAS; France) with an optical radiation filter was used as the UV source. Such a system is a representative of natural sunlight. ${ }^{20}$ The temperature during UV exposure was monitored and averaged at $38^{\circ} \mathrm{C}$. The conditions were 
84 chosen on the basis of an international standard. ${ }^{26}$ De-ionized and purified water

85 (conductivity $<1 \mu \mathrm{S} / \mathrm{cm}$ ) was used for the water spray onto the nanocoated samples. The runoff water was collected in a reservoir, mounted at the bottom of the climate chamber. The whole weathering process was intervened at selected times $(2,4,6$ and 7 months) for analyzing the in-process condition of the test samples and sampling the collected runoff water for its leaching analysis.

\subsection{Leaching}

To quantify the $\mathrm{TiO}_{2}$ content in the leachate water, fixed amounts of samples (100 ml) were collected at selected times (as indicated earlier) and analyzed by using Inductively Coupled Plasma Mass Spectrometry (ICP-MS; Model 7500cx; Agilent Technologies; USA). The operating conditions of the ICP-MS were as follows- Sample volume: $2 \mathrm{ml}$; RF Power: 1550 W; RF Matching: 1.78 V; Carrier Gas: 0.85 1/min; Makeup gas: 0.2 1/min; Nebulizer: Micromist; Nebulizer pump: $0.1 \mathrm{r} / \mathrm{s} ; \mathrm{S} / \mathrm{C}$ temperature: $15^{\circ} \mathrm{C}$; He flow rate: $5 \mathrm{ml} / \mathrm{min} ; \mathrm{H}_{2}$ flow rate: $2 \mathrm{ml} / \mathrm{min}$; Integration time: $0.1 \mathrm{~s}$; Chamber \& Torch: Quartz; Cone: Ni; Element detection threshold limit: $0.5 \mu \mathrm{g} / \mathrm{l}$.

\subsection{Abrasion}

A modified Taber ${ }^{\mathrm{TM}}$ linear abrasion apparatus (Model 5750; Taber Inc. USA) ${ }^{27}$ was used for the abrasion of the nanocoated samples. The standard form of this apparatus is referenced in numerous internationally recognized test standards. ${ }^{28-30}$ This apparatus is already being used in industries for analyzing the performance of products like paint, coating, metal, paper, textile etc., during the application of a mechanical stress. ${ }^{31}$ The normal stress of the abradant of about $15-500 \mathrm{kPa}$, being applied through Taber, also corresponds to the typical normaland thus tangential- stress levels applied to surface coatings in a domestic setting, e.g. walking 
with shoes, displacement of different furnishings etc. ${ }^{3,32}$ It incorporates a motor driven

110 horizontal arm (bar) that displaces an abradant in a back and forth linear motion over the test

111 sample. The abrasion is caused by the friction at the contact surface between the surfaces of

112 the abradant and the sample. Via a vertical shaft, a known weight is mounted on the top of the

113 abradant which shall be referred to as the Normal Load in the following text. The Taber ${ }^{\mathrm{TM}}$

114 H38 non-resilient vitrified clay-carborundum abradant was used during the abrasion of the

115 nanocoated samples. This abradant comes in a cylindrical shape (6 mm diameter, $2 \mathrm{~cm}$ length)

116 and comprises of very fine abrasive particles $(\sim 4 \mu \mathrm{m})$ of carborundum that provide mild

117 abrasion. For reproducing the domestic stress conditions, a normal load of $6 \mathrm{~N}$ was chosen.

118 An abrasion stroke length of $76 \mathrm{~mm}$, abrasion speed of 60 cycles/min and abrasion duration of

11910 min were other selected parameters.

\subsection{Experimental set-up}

122 Figure 1 shows the scheme of the complete experimental set-up. Particle free air is passed

123 through a nanosecured work post (HPPE 10, Erma Flux S.A., France) containing the Taber

124 abrasion apparatus. Already been successfully employed in various nanoparticles' dustiness

125 tests, ${ }^{33}$ this work post has a particle filter efficiency of $99.99 \%$. The air flow rate inside this

126 work post is equal to $31000 \mathrm{l} / \mathrm{min}$. The test sample is placed inside a self designed Emission

127 Test Chamber $(0.5 \mathrm{~m} \times 0.3 \mathrm{~m} \times 0.6 \mathrm{~m}) .{ }^{34}$ A small fraction of the air circulating inside the

128 nanosecured work post passes through the emission test chamber before starting the abrasion

129 tests in order to make it free from background particles. As soon as the chamber becomes

130 particle free, it is sealed completely. A slot is also provided on one of the walls of this

131 chamber allowing the horizontal arm of the abrasion apparatus passing through and operating

132 the motor unit placed externally. A radial symmetric sampling hood with a volume of $713 \mathrm{~cm}^{3}$

133 provides an encapsulation of the sampling suction zone around the abradant. Such sampling 
134 hood has also been employed in other studies with varying volumes, such as $1500 \mathrm{~cm}^{3}$ by

135 Vorbau et al. ${ }^{3}$ and $60 \mathrm{~cm}^{3}$ by Gohler et al. ${ }^{35}$. Its use minimizes particle loss to the emission

136 test chamber's walls or other surfaces. Furthermore, the aerosol concentration remains

137 relatively high due to the low volume of the sampling hood and the fixed total sample flow

138 that amounts to $6.8 \mathrm{l} / \mathrm{min}$. The Taber apparatus along with the emission test chamber

139 constitute the Aerosol Generation Section $(A G S)$. The AGS is connected to an Aerosol

140 Measurement Section (AMS) using anti-static electrically conductive tubes (6 mm diameter)

141 where the generated aerosol particles are characterized in terms of their number concentration

142 and size distribution. The particle number concentration $(P N C)$ can be defined as the number

143 of particles present in a unit centimeter cube of air at a given instant of time. The particle size

144 distribution (PSD) is the classification of the PNC according to their size. The instruments

145 used to measure these two quantities were: Condensation Particle Counter (CPC), Scanning

146 Mobility Particle Sizer (SMPS), Aerodynamic Particle Sizer (APS) and a Mini Particle

147 Sampler (MPS ${ }^{\circledR} ;$ Ecomesure Inc. France) ${ }^{36}$ The details on these instruments and their

148 operation conditions are shown in figure 1. Whilst the CPC measures the emitted aerosol

149 particles number concentration (EAPNC), the PSD is measured using SMPS and APS. A

150 MPS is used for the particle collection through filtration technique on copper mesh grids

151 which can be used later in TEM for various qualitative analyses of the emitted aerosol

152 particles without any limitation on the aerosol size. Therefore, the whole aerosol measurement

153 section, quantifying the particle emission, can measure aerosol particles having sizes ranging

154 from $4 \mathrm{~nm}$ to $20 \mu \mathrm{m}$.

155

$156 \quad$ 2.6. Background and particle loss

157 Three empty test runs were done before the main abrasion experiment to measure the

158 concentration of the background particles and those generated by the motor in abrasion 
apparatus. Without the test sample present in the chamber, the average concentration, detected

160 by CPC within the sampling hood, was $\sim 0.7 \mathrm{~cm}^{-3}$ with a standard deviation of $0.2 \mathrm{~cm}^{-3}$.

161 Therefore, the concentrations of all the background particles and those generated by the

162 abrasion apparatus were insignificant. The calculations on the loss of particle concentration,

163 due to their deposition on the walls of the chamber, have shown a loss of $4 \%$ in number

164 during 10 min (i.e. the duration of the abrasion process).

165 For the present experimental set-up, the particle loss in the connecting tubes (i.e. losses due to 166 their gravitational settling, inertial deposition etc.) has been calculated by Shandilya et al. ${ }^{37}$

167 on the basis of system of equations enlisted by Brockmann et al. ${ }^{38}$ Shandilya et al. ${ }^{37}$ found it 168 to be $17 \%$ for particles having size less than or equal to $10 \mathrm{~nm}$. For the $100 \mathrm{~nm}$ sized particles 169 or bigger, the loss reduces to mere $1 \%$.

170

171 3. Results and Discussion

\section{3.1. Structural deterioration of nanocoated sample surfaces}

173 In figure 2 (a) to (e), the evolution in the surface deterioration of the nanocoated sample can

174 be observed with the increase in weathering duration. The optical microscopic image of a

175 non-weathered sample (figure 2 (a)) shows a continuous and intact form. With 2 months of

176 weathering (figure 2 (b)), ridges and valleys start to appear on the surface. If the weathering

177 continues, they develop into the cracks by 4 months of weathering (figure 2 (c)). After 6

178 months, these cracks start to broaden up with branching at different parts (figure 2 (d)). By 7

179 months, the nanocoating is no longer continuous but reduced in the form of lumps (figure 2

180 (e)). On the contrary, for an uncoated reference sample, no such effect of weathering was

181 observed throughout the whole process. In the literature, the cracking of water based

182 nanocoatings (as in present case) has been attributed mainly to two factors: drying stress due

183 to water content evaporation ${ }^{39-42}$ and gradual embrittlement of the polymeric binder present 
184 in the nanocoating during its interaction with UV rays. ${ }^{43}$ Moreover, the cracking is often

185 accompanied by the shrinking or compaction of the nanocoating on the surface due to the 186 evaporation of the water content, as observed by Murray ${ }^{40}$ and Dufresne et al. ${ }^{41}$

187 The nanocoating's shrinking and cracking may result in the exposure of the brick surface,

188 lying underneath. In order to confirm this hypothesis, EDS analysis of the weathered

189 nanocoated sample surfaces was done to create an elemental map between Ti (contributed by

190 the nancoating) and Ca (contributed by the brick). This would show the change in completely

191 exposed surfaces of the brick substrate. The results are shown in figure 2 (f) to (j). One may

192 see that while the Ti content on the surface remains approximately the same throughout the

193 weathering (average value $\sim 16.1 \%$ ), the Ca content and the exposed surface increase

194 proportionately. It directly implies the shrinkage of the nanocoating with weathering. If

195 continued further, the increased shrinking may even lead to the increase in $\mathrm{Ti} \%$ density in the 196 nanocoating lumps.

\subsection{Particles emission into water by leaching}

For measuring the emission of $\mathrm{TiO}_{2}$ nanoparticles in the water, $100 \mathrm{ml}$ of leachate samples were taken from the collected runoff water at selected times from a reservoir which was kept beneath the nanocoated samples. For a detection threshold of $0.5 \mu \mathrm{g} / \mathrm{l}$ of an element, Ti was found to be always below this threshold in the sample volume whereas the leached amount of $\mathrm{Ca}$ (contributed by the brick) was found to be proportionally increasing with the weathering

204 duration. The TEM and EDS analysis of various droplets from the leachate samples (test 205 methodology and results described in supplementary information) showed irregularly shaped microsized particle agglomerates.

207 In coherence with the ICP-MS measurements, the EDS analysis of these particle agglomerates 208 also showed an overall increasing Ca content, from 3 to $17 \%$ (by mass), with weathering. A 
meager $\mathrm{Ti}$ content $(0.2-1 \%$, by mass) was observed in all particle agglomerates. The $\mathrm{C}$ content

210 (from nanocoating copolymer) was found to be varying from 3 to $10 \%$ by mass. The other

211 dominating elements were $\mathrm{Si}(\sim 32 \%$, by mass) and $\mathrm{Al}$ ( 20\%, by mass). An increased water

212 conductivity (from $<1$ to $13 \mu \mathrm{S} / \mathrm{cm}$ ) was also observed in the leachate samples which is

213 supposed to be a consequence of the increased presence of $\mathrm{Si}, \mathrm{Al}$ and $\mathrm{Ca}$.

214 This concludes that despite the deterioration by weathering, the nanocoated sample surfaces

215 are still strong enough to resist the leaching of the constituent nanoparticles in the runoff

216 water. Infact, it is the brick that obviously leaches its constituents in the runoff water. These

217 results seem to be consistent with Al-Kattan et al. ${ }^{10}$ which studied the release of Ti, from

218 paints containing $\mathrm{TiO}_{2}$ nanoparticles, into runoff water under the effect of artificial

219 weathering. They showed a close to background release of $\mathrm{Ti}$, indicating that $\mathrm{TiO}_{2}$

220 nanoparticles are strongly bound in the paint.

\subsection{Particles emission into air by abrasion}

Both uncoated reference and nanocoated samples were abraded after they were exposed to

weathering with varying durations. In figure 3 (a) and (b), TEM images of the emitted aerosol

particles are shown which were sampled and collected on mesh grids during the first 2

minutes of abrasion of the 4 and 7 months weathered nanocoated samples, respectively, under

the same sampling conditions. More aerosol particles get deposited on the mesh grids when the weathering duration is increased from 4 to 7 months. When zoomed, irregularly shaped polydispersed aerosol particles with no specific evolution in the shape, over the variation of

230 the weathering duration, were observed. Most importantly, for 7 months weathered

231 nanocoated samples, the presence of a considerable amount of free nanoparticles of $\mathrm{TiO}_{2}(\mathrm{Ti}$

232 mass $>90 \%$ ) was observed (figure 3 (c) \& (d)). Since this result is in contrary to the findings

233 of numerous studies $4,31,35,44$, it is of more particular interest as these studies show that a large 
234 fraction of the emitted nanomaterial is present in the matrix-bound form and not in the free

235 state. The increase in the relative \% density of Ti, during the shrinking of the nanocoating

236 with the weathering, (as hypothesized earlier) may lead to the generation of these free $\mathrm{TiO}_{2}$

237 nanoparticles.

238 The results on the chemical composition of the aerosol particles, generated from the abrasion

239 of 4 and 7 months weathered nanocoated samples, are shown in figure 3 (e). In this figure, the

240 average mass percentages of 3 elements- C (essentially coming from the nanocoating's

241 copolymer), $\mathrm{Ti}$ (essentially coming from the nanocoating) and $\mathrm{Ca}$ (essentially coming from

242 the brick)- are shown. One can observe a sharp drop in the relative $\mathrm{C}$ content (from $56 \%$ to

$24312 \%$ ) while a sharp rise in the relative Ti content (from $7 \%$ to $55 \%$ ) when the weathering

244 duration increases from 4 months to 7 months. Also, the relative Ca content, which is absent

245 in the case of 4 months weathered nanocoated samples, starts appearing and attains a value of

$2466 \%$ with 7 months of weathering. Hence, a direct impact of the weathering duration on the

247 size and chemical composition of the aerosol particles can be observed from these results.

248 Moreover, the chances of the exposure of free $\mathrm{TiO}_{2}$ nanoparticles are much higher in the case

249 of 7 months weathered nanocoated samples.

250 The results on the EAPNC and PSD, measured within the volume of the sampling hood, are

251 shown in figure 4. In figure 4 (a) and (b), the abrasion test starts at $t=120 \mathrm{~s}$ and ends at $\mathrm{t}=720$

252 s. Before and after this time interval (i.e. $\mathrm{t}=0$ to $120 \mathrm{~s}$ and $\mathrm{t}=720$ to $840 \mathrm{~s}$ ), the abrasion

253 apparatus is at rest. For the uncoated reference samples, a constant EAPNC $\left(\sim 500 \mathrm{~cm}^{-3}\right.$; std.

254 deviation: 5 to $16 \mathrm{~cm}^{-3}$; repeated thrice) is observed, regardless the weathering durations.

255 Hence, the artificial weathering has no apparent effect on the emitted aerosol particles from

256 the uncoated reference sample. However, for the nanocoated samples, the EAPNC increases

257 with the weathering duration. Except for 6 and 7 months, the nature of its variation with time 
258 is also strikingly similar i.e. ascends initially, becomes constant, ascends again and becomes

259 constant at last (the PSD, during the first constant phase, is shown in figure 4(d)).

260 For 6 and 7 months weathered nanocoated samples, we observe a rise in the EAPNC curves

261 during their initial phases $(\mathrm{t}=120 \mathrm{~s}$ to $\mathrm{t}=360 \mathrm{~s})$ beyond the maximum level observed for the

262 shorter weathering durations. After $\mathrm{t}=360 \mathrm{~s}$, these curves tend back to the same level as that

263 of the uncoated reference and their counterparts. Such a behavior can be explained on the

264 basis of the nanocoating removal mechanism during the abrasion of the weathered nanocoated

265 samples. In case of non-weathered, 2 and 4 months weathered nanocoated samples, the

266 dominant material removal mechanism is assumed to be abrasion wear of the nanocoating

267 due to its continuous and stable form. But for 6 and 7 months weathered nanocoated samples,

268 it is hypothesized that the dominant material removal is rather uprooting of the nanocoating

269 lumps (or soon to be lumps) by the abradant. Since these lumps are loosely attached to the

270 surface, their uprooting is faster and easier. As a result, the EAPNC reaches its highest level

271 as soon as the abrasion starts and comes back to the same level, later, as that of the uncoated

272 reference, when all the nanocoating lumps have been uprooted and the brick surface is

273 completely exposed. The PSD, shown in figure 4 (c) and (d) for uncoated reference and

274 nanocoated samples respectively, vary in a different manner with respect to each other. Whilst

275 for the uncoated reference samples, there is no significant change in the size mode (alternating

276 between $250 \mathrm{~nm}$ to $350 \mathrm{~nm}$ ) and maximum PNC (lying around $375 \mathrm{~cm}^{-3}$, std. dev.: 0.2 to 8

$277 \mathrm{~cm}^{-3}$ ), a continuous evolution can be observed in these two parameters in case of the

278 nanocoated samples.

279 Coming back to the nature of the EAPNC variation with time, as observed in figure 4 (b), an 280 analytic model had been presented by Shandilya et al. ${ }^{46}$ which approximates such a variation

281 in terms of 4 phases for the present nanocoating and one other commercial one: Tipe ${ }^{\circledR}$ E502,

282 TitanPE Technologies, Inc. (see figure 5). When an uncoated reference sample is abraded 
(figure 4 (a)), the EAPNC reaches a maximum limit swiftly (represented by segment EF in

284 figure 5(a); named as phase I) and then remains constant until the end of the abrasion (represented by segment FI in figure 5(a); named as phase IV). However, the EAPNC, in case of a nanocoated sample (figure 4 (b)), passes through two intermediate phases (represented by segments FG \& GH in figure 5(b); named as phases II and III resp.) before becoming constant at the end i.e. phase IV. Obviously, for an uncoated surface, the phases II and III are absent in the evolution of the EAPNC.

If physically interpreted, the phase I is contributed by the evolution of the contact surface conditions between the abradant and the nanocoated sample surface when the abrasion starts. During this phase, an ascending EAPNC is observed. In phase II, the EAPNC is constant and the abrasion of the nanocoated sample surface takes place under a stable state. The nanocoating is getting removed gradually or slowly through its abrasion wear. The duration of this phase also signifies the apparent nanocoating life. By the end of phase II, the surface nanocoating layer is no more stable and just the nanocoating-brick interface is left. With the advent of phase III, the brick surface starts to get exposed gradually and by the end of this phase, it is completely exposed. Therefore, the EAPNC, during phase IV, arrives at the same

299 level as that of an uncoated reference sample and remains constant afterwards.

300 Three quantities:

301 (i) Emission Transition Pace $(\boldsymbol{E T P})$ i.e. $(\Delta C / \Delta t)_{I}$;

302 (ii) Stable Emission Level (SEL) i.e. $(\# C)_{I I}$;

303 (iii) Stable Emission Duration (SED) i.e. $T_{I I}$

304 can also be identified from figure 5 (a) and (b) and are discussed in the following. These are 305 the important indicators for assessing the nanocoating useful life and EAPNC. In figure 6 (a) 306 and (b), they are plotted as a function of the weathering duration. In figure 6 (a), we see that 307 the $\boldsymbol{E T P}$ (defined as the rate of change of the EAPNC) increases with weathering duration for 
weathered nanocoated samples whereas for the uncoated reference, it remains constant.

309 Moreover, ETP values for non-weathered, 2 and 4 months weathered nanocoated samples lie 310 beneath the uncoated reference sample. But for 6 and 7 months weathered nanocoated 311 samples, they lie above. On the basis of figure 2 and 4, we have already hypothesized a 312 change in the nanocoating removal mechanism during the transition of the weathering 313 duration from 4 to 6 months. Therefore, one may conclude that if the ETP value of the 314 EAPNC, from a nanocoated sample, lies beneath the one corresponding to its uncoated reference substrate, the nanocoating removal mechanism is dominated by the abrasion wear.

316 If opposite, the uprooting of the nanocoating is more dominant. Under given abrasion 317 conditions, if ETP does not increase with the weathering duration (as observed in case of the 318 uncoated reference), it implies no change in the abrasion conditions, regardless of the 319 weathering duration. But if it increases (as observed in case of the weathered nanocoated 320 samples), it implies the change in the abrasion conditions. In the present case, such a change 321 is imparted by the deterioration of the nanocoating, as shown, qualitatively, in figure 2 . The 322 second quantity, $\boldsymbol{S E D}$, is a direct indicator of the nanocoating life - higher the $S E D$, higher is 323 the nanocoating life time. It appears to decrease with the weathering duration (figure 6 (b)). 324 When $\mathrm{SED}=0$, it means that the nanocoating disappears as soon as its abrasion starts. 325 Quantitatively, it allows extrapolating the effect of the shorter weathering durations to that of 326 the longer ones without prolonging the weathering test in reality. In figure 6 (b), if the SED 327 average values, from first 2 months of weathering, are extrapolated, we observe that SED 328 reduces to 0 in 11 months. The extrapolation of the extreme limits (i.e. through maximum 329 value of SED for 0 months and minimum value of SED for 2 months) can be used to calculate 330 the minimum useful life of the nanocoating under present weathering conditions. If it is done 331 in the present case, we observe that SED reduces to 0 in 6 months- this is exactly what we 332 observe in the figure 6 (b). Moreover, the average value of SED is decreasing from $320 \mathrm{~s}$ to 
110 s (i.e. a reduction factor of $\sim 3$ ) in mere first 4 months of weathering. The EAPNC during

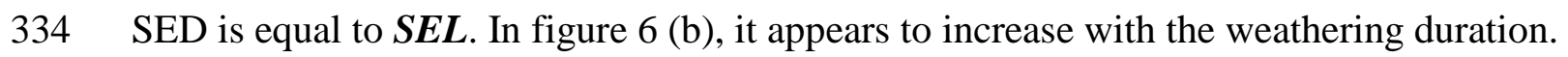

335 Since $\mathrm{SED}=0$ for 6 and 7 months of weathering, therefore, SEL value for these durations

336 cannot be calculated.

337 If summarized, we can say that under the present experimental conditions, a step-wise and

338 complete surface deterioration of the nanocoated samples was observed as a function of the

339 duration of a weathering by UV, temperature and water. This surface deterioration led directly

340 to an increase of the emitted aerosol particles number concentration (measured within the

341 volume of the sampling hood) and the $\mathrm{TiO}_{2}$ content of the aerosolized wear particles. A

342 considerable presence of free $\mathrm{TiO}_{2}$ nanoparticles was observed in the case of the 7 months

343 weathered nanocoated samples. This was a fundamental change observed in the chemical

344 composition of the aerosol particles, as for short weathering durations, $\mathrm{TiO}_{2}$ nanoparticles

345 were always found to be embedded inside the released coarse wear particles with a polymeric

346 matrix. This increase might still continue for longer weathering durations. With a high

347 specific surface area, these free nanoparticles aerosols now accentuate a potential risk in terms

348 of nano- toxicity. In case of leaching, no such effects were observed during 7 months of

349 weathering. However, fears still remain on how and in what concentrations the leaching of

$350 \mathrm{TiO}_{2}$ might occur during prolonged weathering durations. This study also proposed an outline

351 to understand the phenomenon of aerosolization and the indicators, like Emission Transition

352 Pace, Stable Emission Level and Stable Emission Duration, for its monitoring. They were

353 found to be significant to quantitatively predict the emitted aerosol particles number

354 concentration and nanocoating useful life by the means of linear extrapolation from shorter

355 weathering durations. It is possible to extend this study to a broad spectrum of nanocoatings,

356 with the prospect of seeking their optimal formulations on the basis of nano risk i.e. emissions

357 control. 


\section{Acknowledgements}

360 This work has been carried out in the framework of the Labex SERENADE (ANR-11-LABX-

361 0064) and the A*MIDEX project (ANR-11-IDEX-0001-02), funded by the French

362 Government program, Investissements d'Avenir, and managed by the French National

363 Research Agency (ANR). The authors would like to thank the French Ministry of

364 Environment (DRC 33 and program 190) and ANSES (Nano-data project 2012/2/154, APR

365 ANSES 2012) for financing the work. We are equally grateful to Olivier Aguerre-Chariol,

366 Patrice Delalain, Pauline Molina and Farid Ait-Ben-Ahmad for their cooperation and advice

367 during the experiments.

369 Supporting Information Available

370 More details on the materials used during the study can be found in the supporting

371 information. This information is available free of charge via the Internet at

372 http://pubs.acs.org/.

374 Acknowledgements

375 [1] Torgal, F.P.; Jalali, S. Eco-efficient construction and building materials. Constr. Build. $376 \quad$ Mater. 2011, 25, 582-590.

377 [2] Stamate, M.; Lazar, G. Application of titanium dioxide photocatalysis to create self378 cleaning materials. Romanian Technical Sciences Academy MOCM 2007, 13-3, 280-285.

379 [3] Vorbau, M.; Hillemann, L.; Stintz, M. Method for the characterization of the abrasion $380 \quad$ induced nanoparticle release into air from surface coatings. Aerosol Sci 2009, 40, 209381217. 
[4] Shandilya, N.; Le Bihan, O.; Morgeneyer, M. A review on the study of the generation of (nano-) particles aerosols during the mechanical solicitation of materials. J Nanomater 2014, Art. ID 289108.

[5] Le Bihan, O.; Shandilya, N.; Gheerardyn, L.; Guillon, O.; Dore, E.; Morgeneyer, M.. Investigation of the Release of Particles from a Nanocoated Product. Advances in Nanoparticles 2013, 2, 39-44.

[6] Göhler, D.; Nogowski, A.; Fiala, P.; Stintz, M. Nanoparticle release from nanocomposites due to mechanical treatment at two stages of the life-cycle. J Phys Conf Ser 2013429 (2013) 012045; DOI: 10.1088/1742-6596/429/1/012045.

[7] Allen, N.S.; Edge, M.; Corrales, T.; Childs, A.; Liauw, C.M.; Catalina, F.; Peinado, C.; Minihan, A.; Aldcroft, D. Ageing and stabilisation of filled polymers: an overview. Polym Degrad Stabil 1998, 61, 183-199.

[8] Allen, N.S.; Edge, M.; Ortega, A.; Sandoval, G.; Liauw, C.M.; Verran, J.; Stratton, J.; McIntyre, R.B. Degradation and stabilisation of polymers and coatings: nano versus pigmentary titania particles. Polym Degrad Stabil 2004, 85, 927-946.

[9] Hsu, L.Y.; Chein, H.M. Evaluation of nanoparticle emission for $\mathrm{TiO}_{2}$ nanopowder coating materials. J Nanopart Res 2007, 9, 157-163.

[10] Al-Kattan, A.; Wichser, A.; Vonbank, R.; Brunner, S.; Ulrich, A.; Zuind, S.; Nowack, B. Release of $\mathrm{TiO}_{2}$ from paints containing pigment- $\mathrm{TiO}_{2}$ or nano- $\mathrm{TiO}_{2}$ by weathering. Env Sci Process Impact 2013, 15, 2186-2193.

[11] Kaegi, R.; Ulrich, A.; Sinnet, B.; Vonbank, R.; Wichser, A.; Zuleeg, S.; Simmler, H.; Brunner, S.; Vonmont, H.; Burkhardt, M.; Boller, M. Synthetic $\mathrm{TiO}_{2}$ nanoparticle emission from exterior facades into the aquatic environment. Environ Pollut 2008, 156, 233-239. 
[12] Hirth, S.; Cena, L.; Cox, G.; Tomovic, Z.; Peters, T.; Wohlleben, W. Scenarios and methods that induce protruding or released CNTs after degradation of nanocomposite materials. J Nanopart Res 2013, 15, 1504-1518.

[13] Wohlleben, W.; Brill, S.; Meier, M. W.; Mertler, M.; Cox, G.; Hirth, S.; von Vacano, B.; Strauss, V.; Treumann, S.; Wiench, K.; Ma-Hock, L.; Landsiedel, R. On the lifecycle of nanocomposites: comparing released fragments and their in vivo hazards from three release mechanisms and four nanocomposites. Small 2011, 7, 2384-2395.

[14]Al-Kattan, A.; Wichser, A.; Zuin, S.; Arroyo, Y.; Golanski, L.; Ulrich, A.; Nowack, B. Behavior of $\mathrm{TiO} 2$ released from nano-TiO2-containing paint and comparison to pristine nano- $\mathrm{TiO}_{2}$. Environmental Science \& Technology 2014, 48, 6710-6718.

[15] Gondikas, A. P.; von der Kammer, F.; Reed, R. B.; Wagner, S.; Ranville, J. F.; Hofmann, T. Release of $\mathrm{TiO}_{2}$ nanoparticles from sunscreens into surface waters: a one-year survey at the old danube recreational lake. Environmental Science \& Technology 2014, 48, 54155422.

[16] von Goetz, N.; Lorenz, C.; Windler, L.; Nowack, B.; Heuberger, M.; Hungerbuhler, K. Migration of $\mathrm{Ag}$ - and $\mathrm{TiO}_{2}$ - (nano)particles from textiles into artificial sweat under physical stress: experiments and exposure modeling. Environmental Science \& Technology 2013, 47, 9979-9987.

[17] Windler, L.; Lorenz, C.; von Goetz, N.; Hungerbuhler, K.; Amberg, M.; Heuberger, M.; Nowack, B. Release of titanium dioxide from textiles during washing. Environmental Science \& Technology 2012, 46, 8181-8188.

[18]Zhang, W.; Crittenden, J.; Li, K. G.; Chen, Y. S.; Attachment efficiency of nanoparticle aggregation in aqueous dispersions: modeling and experimental validation. Environmental Science \& Technology 2012, 46, 7054-7062. 
[19] Stefano, Z.; Marco, G.; Arlen, F.; Luan, G. Leaching of nanoparticles from experimental water-borne paints under laboratory test conditions. Journal of Nanoparticle Research 2013, 16, 2185.

[20]Petkovic, J.; Zegura, B.; Stevanovic, M.; Drnovsek, N.; Uskokovic, D.; Novak, S. DNA damage and alterations in expression of DNA damage responsive genes induced by $\mathrm{TiO}_{2}$ nanoparticles in human hepatoma HepG2 cells. Nanotoxicology 2011, 5, 341-353.

[21]Unnithan, J.; Rehman, M.U.; Ahmad, F.J.; Samim, M. Aqueous Synthesis and Concentration-Dependent dermal toxicity of $\mathrm{TiO}_{2}$ nanoparticles in wistar rats. Biol Trace Elem Res 2011, 143, 1682-1694.

[22] Warheit, D.B.; Brock, W.J.; Lee, K.P.; Webb, T.R.; Reed, K.L. Comparative pulmonary toxicity inhalation and instillation studies with different $\mathrm{TiO}_{2}$ particle formulations. Toxicol Sci 2005, 88, 514-524.

[23] Yamashita, K.; Yoshioka, Y.; Higashisaka, K.; Mimura, K.; Morishita, Y.; Nozaki, M.; Yoshida, T.; Ogura, T.; Nabeshi, H.; Nagano, K.; Abe, Y.; Kamada, H.; Monobe, Y.; Imazawa, T.; Aoshima, H.; Shishido, K.; Kawai, Y.; Mayumi, T.; Tsunoda, S.; Itoh, N.; Yoshikawa, T.; Yanagihara, I.; Saito, S.; Tsutsumi, Y. Silica and titanium dioxide nanoparticles cause pregnancy complications in mice. Nat Nanotechnol 2011, 6, 321-328.

[24]Barnard, A.S. One-to-one comparison of sunscreen efficacy, aesthetics and potential nanotoxicity. Nat Nanotechnol 2010, 5, 271-274.

[25] Auffan, M.; Rose, J.; Bottero, J.Y.; Lowry, G. V.; Jolivet, J.P.; Wiesner, M. R. Towards a definition of inorganic nanoparticles from an environmental, health and safety perspective. Nat Nanotechnol 2009, 4, 634-641.

[26] AFNOR. Paints and varnishes - Methods of exposure to laboratory light sources - Part 1: General guidance, ISO 16474-1, 2012. 
454 [27] Morgeneyer, M.; Shandilya, N.; Chen, Y.M.; Le Bihan, O. Use of a modified Taber

455

456 abrasion apparatus for investigating the complete stress state during abrasion and inprocess wear particle aerosol generation. Chem Eng Res Des, DOI: http://dx.doi.org/10.1016/j.cherd.2014.04.029

[28] ASTM. International. Standard Test method for the abrasion of organic coatings by the Taber Abradant, ASTM D4060, 2007.

[29] ASTM. International. Standard Test Methods for Dry Abrasion Mar Resistance of High Gloss Coatings, ASTM D6037, 1996.

[30] ASTM. International, Standard Test Method for Resistance of Transparent Plastics to Surface Abrasion, ASTM D1044, 2008.

[31] Golanski, L.; Guiot, A.; Pras, M.; Malarde, M.; Tardif, F. Release-ability of nano fillers from different nanomaterials (toward the acceptability of nanoproduct). J Nanopart Res 2012, 14, 962-970.

[32] Hassan, M.M.; Dylla, H.; Mohammad, L.N.; Rupnow, T. Evaluation of the durability of titanium dioxide photocatalyst coating for concrete pavement. Constr Build Mater 2010, $24,1456-1461$.

[33] Morgeneyer, M.; Le Bihan, O.; Ustache, A.; Aguerre Chariol, O. Experimental study of the aerosolization of fine alumina particles from bulk by a vortex shaker. Powder Technol 2013, 246, 583-589.

[34]Le Bihan, O.; Morgeneyer, M.; Shandilya, N.; Aguerre Chariol, O.; Bressot, C. In Handbook of Nanosafety-Measurement, Exposure and Toxicology; Vogel, U., Savolainen, K., Wu, Q., Van Tongeren, M., Brouwer, D., Berges M., Eds.; Academic Press: San Diego 2014; Ch. 7 
477 [35] Göhler, D.; Stintz, M.; Hillemann, L.; Vorbau, M. Characterization of Nanoparticle

478 Release from Surface Coatings by the Simulation of a Sanding Process. Ann Occup Hyg $4792010,54,615-624$.

480 [36] R'mili, B.; Le Bihan, O.; Dutouquet, C.; Aguerre Charriol, O.; Frejafon, E. Sampling by TEM Grid Filtration. Aerosol Sci Tech 2013, 47, 767-775.

482 [37] Shandilya, N.; Le Bihan, O.; Morgeneyer, M., Effect of the normal load on the release of 483 aerosol wear particles during abrasion. Tribol Lett 2014, 55, 227-234.

484 [38] Brockmann, J.E. In Aerosol Measurement- Principles, Techniques and Applications; 485 Kulkarni, P., Baron, P.A., Willeke, K., Eds.; John Wiley \& Sons: New Jersey 2011, Ch. $486 \quad 6$.

487 [39] White, L.R. Capillary rise in powders. J Colloid Interf Sci 1982, 90, 536-538.

488 [40] Murray, M. Cracking in coatings from colloidal dispersions: An industrial perspective. 489 Proceedings Rideal Lecture, London, 20 April 2009.

490 [41]Dufresne, E.R.; Corwin, E.I.; Greenblatt, N.A.; Ashmore, J.; Wang, D.Y.; Dinsmore, 491 A.D.; Cheng, J.X.; Xie, X.S.; Hutchinson, J.W.; Weitz, D.A. Flow and Fracture in Drying 492 Nanoparticle Suspensions. Phys Rev Lett 2003, 91, 224501-1 - 224501-4.

493 [42] Tirumkudulu, M.S.; Russel, W.B. Cracking in Drying Latex Films. Langmuir 2005, 21, $494 \quad 4938-4948$.

495 [43]Hare, C.H. The Degradation of Coatings by Ultraviolet Light and Electromagnetic $496 \quad$ Radiation. Protective Coatings and Linings 1992.

497 [44] Shandilya, N.; Le Bihan, O.; Bressot, C.; Morgeneyer, M. Evaluation of the particle 498 aerosolization from $\mathrm{n}-\mathrm{TiO}_{2}$ photocatalytic nanocoatings under abrasion. J Nanomater $499 \quad$ 2014, Art. ID 185080. 


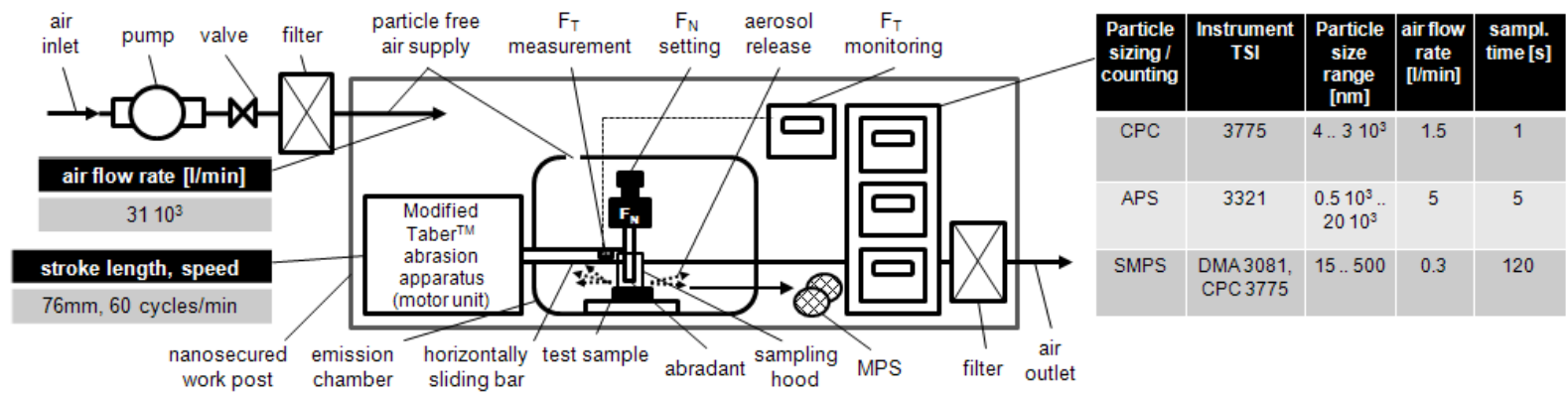

Figure 1. Experimental set-up 


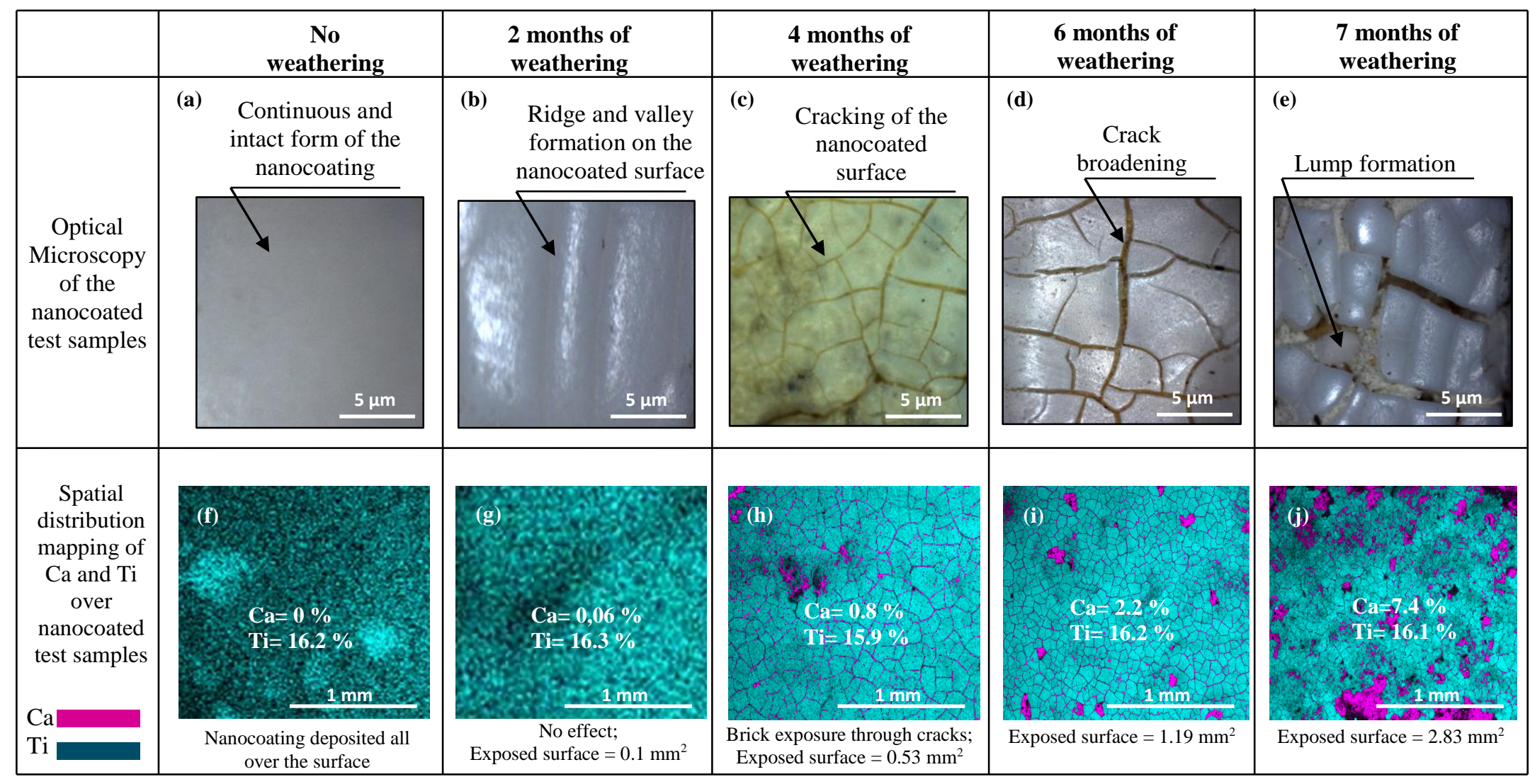

Figure 2. Microscopic analysis of the nanocoated sample 

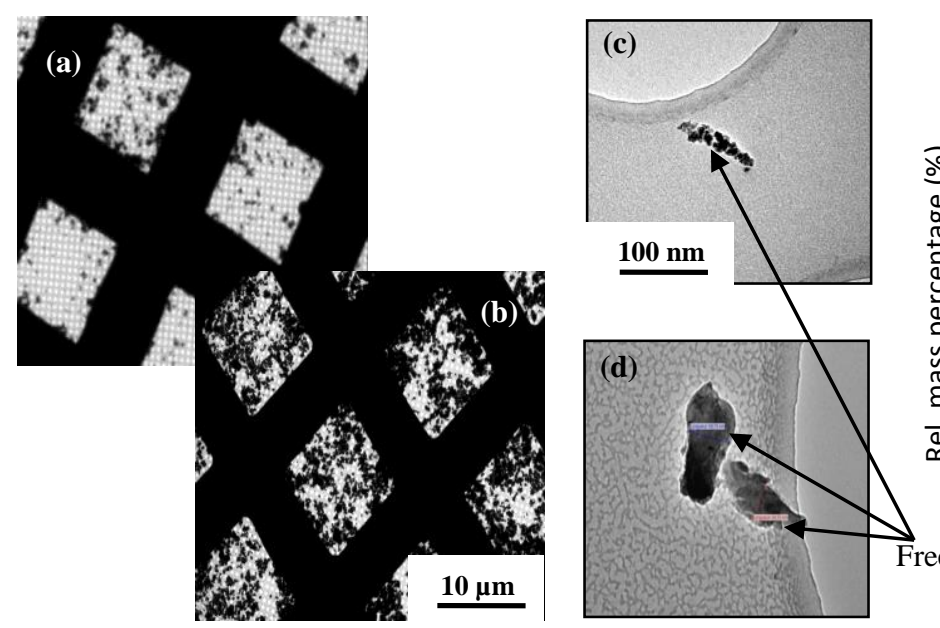

(e) $\square$ months $\square 7$ months

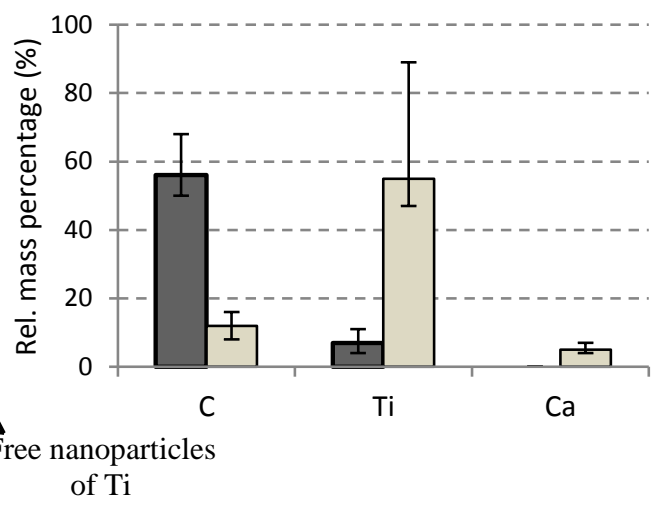

Figure 3. TEM image of the aerosol particles emitted from the abrasion of (a) 4 months (b) 7 months weathered nanocoated samples (c), (d) Free nanoparticles emitted from the abrasion of 7 months weathered nanocoated samples (e) Chemical analysis of the aerosol particles emitted from the abrasion of 4 and 7 months weathered nanocoated samples
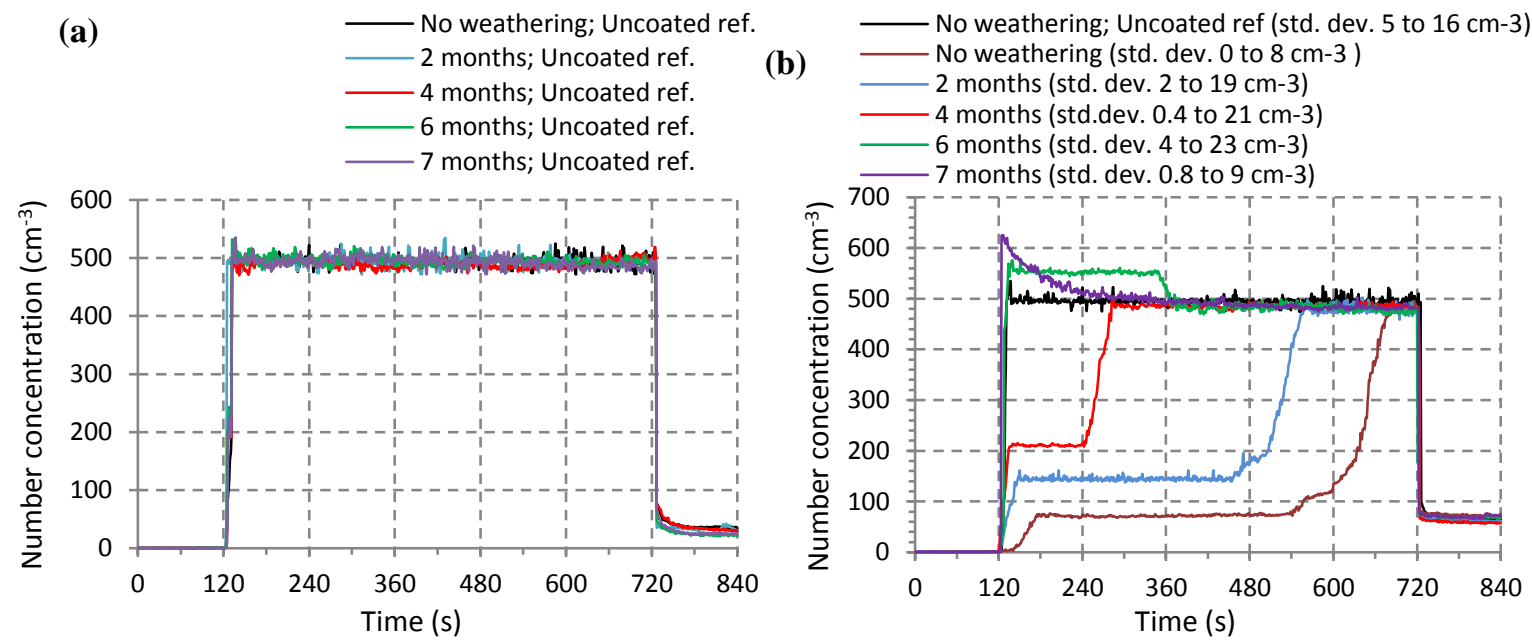

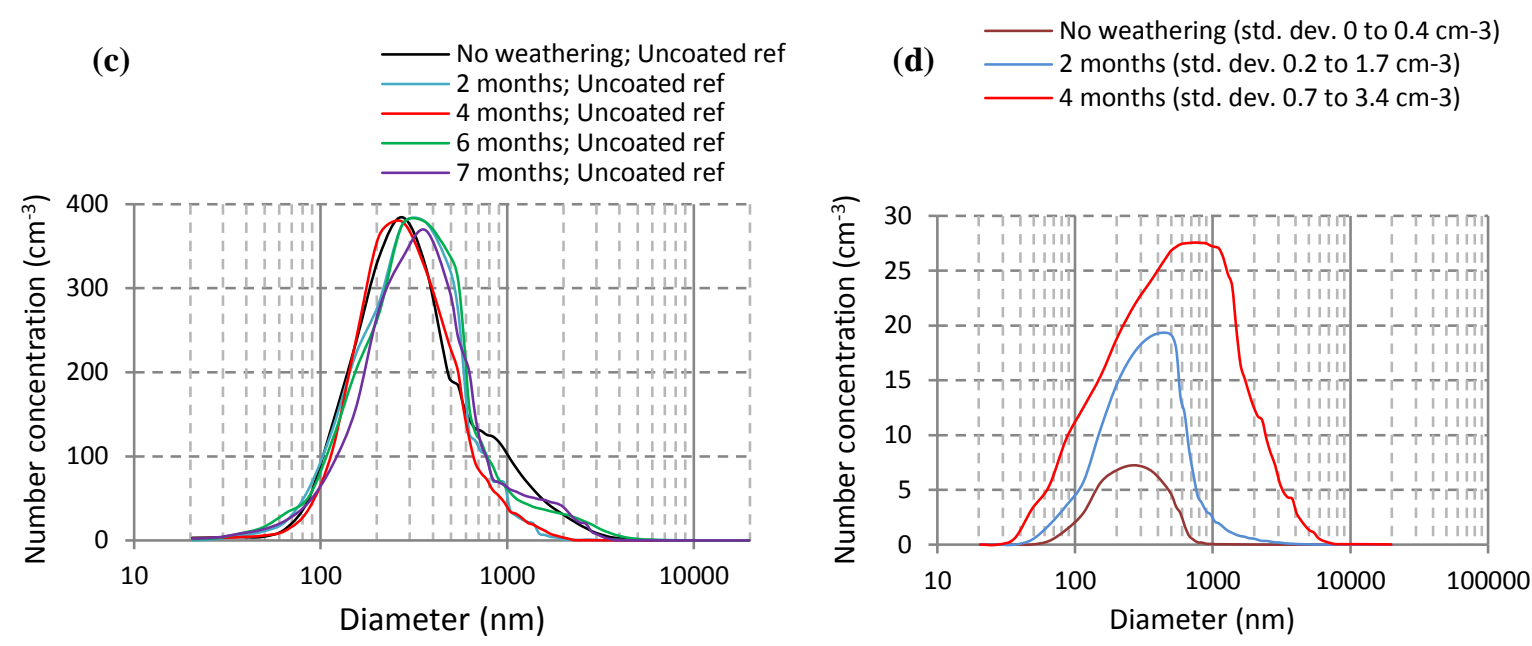

Figure 4. EAPNC during the abrasion of weathered (a) uncoated reference sample (b)

nanocoated samples

PSD of the emitted aerosol particles during the abrasion of weathered (c) uncoated reference sample ( $\mathrm{t}=120 \mathrm{~s}$ to $720 \mathrm{~s})$ (d) nanocoated samples (corresponding to the phase during which the concentration is constant for the first time in figure 4 (b))

(a)

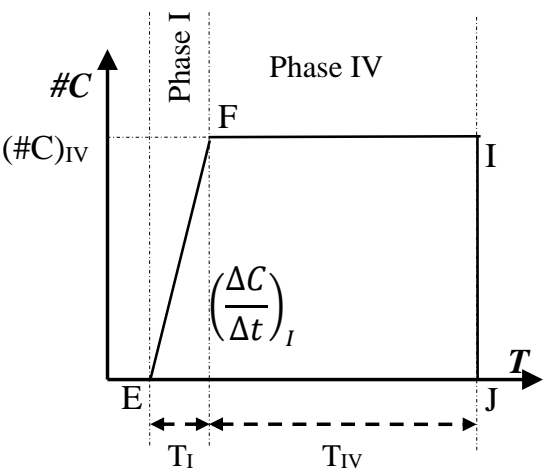

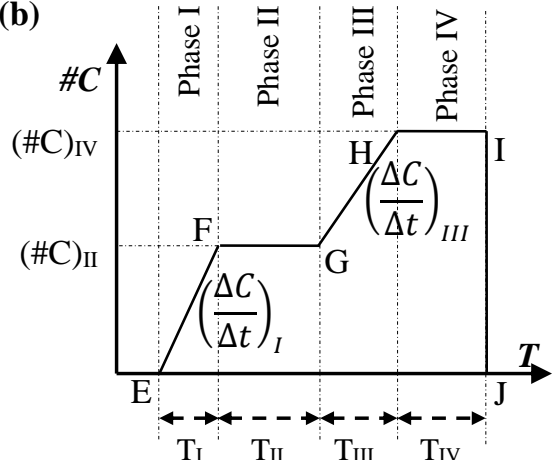

Figure 5. Variation of aerosol particle number concentration generated from (a) uncoated and (b) nanocoated surface samples 

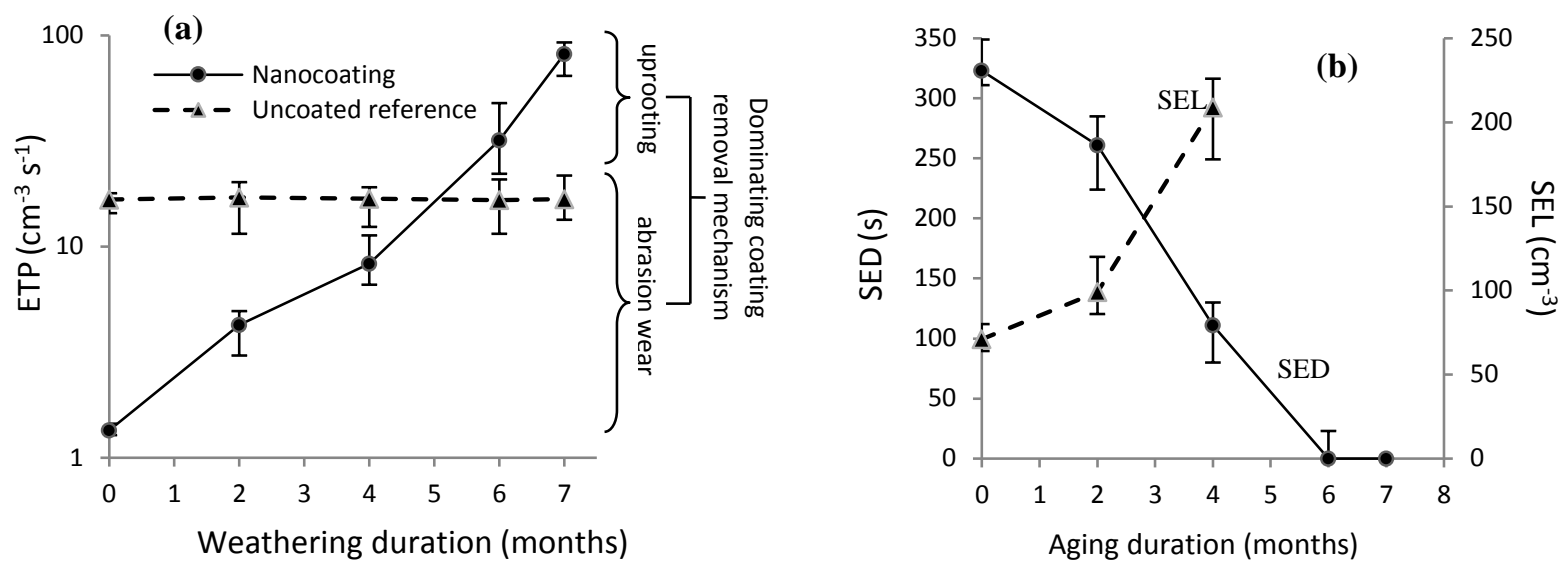

Figure 6. Variation of (a) ETP (b) SED and SEL with the weathering duration 